\title{
PEMBUATAN SISTEM INFORMASI RENTAL KOMIK PADA TAMAN BACAAN CONAN
}

\author{
Muhammad Jibril \\ Program Studi Sistem Informasi, Fakultas Teknik dan IImu Komputer \\ Universitas Islam Indragiri (UNISI) \\ Jl. Provinsi No. 01 Tembilahan Hulu, Indragiri Hilir, Riau - Indonesia \\ Email: Jibril.unisi@gmail.com
}

\begin{abstract}
Reading is a positive activity. In addition to add knowledge, regular reading can strengthen the human brain memory recall. So take an hour to read books, including reading the comics as well. Reading comics is a fun activity, reading, fantasy we fly to follow the story line is written each sheet story. Fans of comics are now growing number because comic fans don't need to spend money to buy his favorite comics. Come to the nearest comic rental house. Register as a member in the rental comic and you can read comics satisfied. One of the rental comic writer is a favorite for Taman Bacaan Conan. This place has members and collection of comics that many. But, the data recording process is still done manually, so workers have difficulty, existing data members are often lost and not returned borrowed books, This is because difficult checking and seeking comic circulation because manual data recording process that resulted in the data accumulated too much. Based on these problems, the writers want to create an application that can help optimize service to members and the data can be stored in a longer time. This application will be made using VB.net and SQL Server 2008 as database.
\end{abstract}

Keywords: Information Systems Comics Rental

\section{PENDAHULUAN}

Membaca merupakan kegiatan positif. Selain menambah wawasan, rutin membaca bisa menguatkan daya ingat memori otak manusia. Jadi luangkan waktu satu jam untuk membaca buku, termasuk membaca komik juga.

Komik adalah sebuah buku cerita bergambar yang memuat kisah-kisah menarik seperti petualangan, komedi, aksi, misteri, olahraga, superhero dan lain-lain. Membaca komik menawarkan sebuah pengalaman lebih dari sekedar membaca buku biasa. Dalam membaca komik, selain membaca teks kita juga dapat menikmati coretan-coretan gambar yang menarik dari para pembuat komik. Bagi sebagian orang, membaca komik merupakan kegemarannya. Membaca komik merupakan kegiatan mengasyikkan, sambil membaca, fantasi kita terbang mengikuti alur cerita yang ditulis setiap lembaran cerita. Penggemar komik sekarang ini sudah semakin banyak karena penggemar komik tidak perlu mengeluarkan uang untuk membeli komik kegemarannya. Datanglah ke rental komik terdekat di rumahmu. Daftar jadi member di rental komik dan kamu bisa puas baca komik. Salah satu rental komik yang menjadi favorit bagi penulis yaitu Taman Bacaan Conan yang berada di jalan perumnas.

\section{TINJAUAN PUSTAKA}

Menurut [1] system adalah himpunan dari aturan-aturan yang memiliki tujuan tertentu, gabungan dari berbagai macam komponen atau unsur yang saling terintegrasi membentuk sebuah kesatuan untuk mencapai tujuan tertentu. Menurut [2] system adalah media yang digunakan sebagai tempat penyimpanan, mengolah dan memberikan informasi yang dibutuhkan oleh pengguna pada organisasi tertentu.

Menurut [3] system adalah kumpulan sub-sub kerja dari aturan-aturan tertentu yang saling berkomunikasi, untuk melakukan sebuah pekerjaan agar dapat mencapai tujuan tertentu.

Menurut [1] system informasi adalah gabungan dari bermacam-macam variable yang saling terintegrasi, saling berkomunikasi satu sama lain, serta saling melengkapi satu sama lain. 


\section{METODE PENELITIAN}

Metode penelitian merupakan langkah-langkah yang akan digunakan dalam pembuatan system informasi ini. Metode penelitian system informasi rental komik bisa dilihat dari gambar berikut :

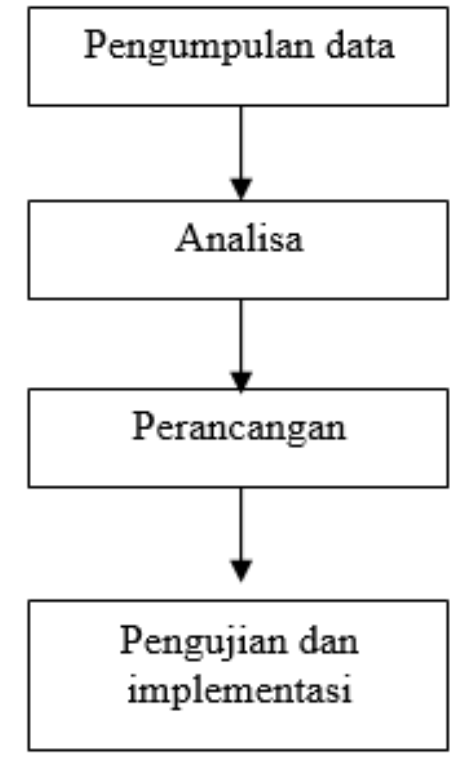

\section{Gambar 1 Metode Penelitian}

\section{HASIL DAN PEMBAHASAN}

1. Flowchart Sistem Yang diusulkan

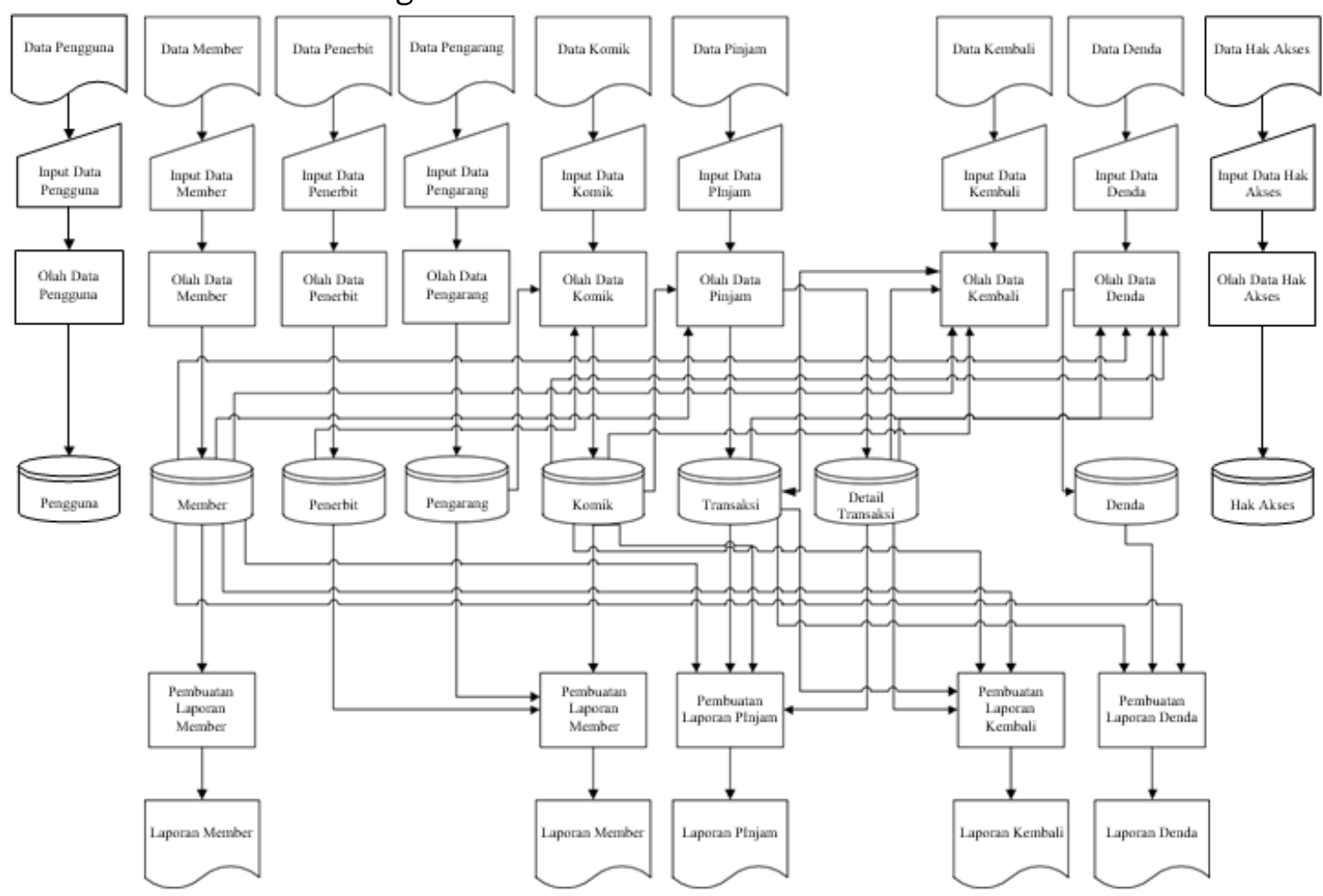

Gambar 2 Flowchart Sistem 
2. Entitas Relationship Diagram

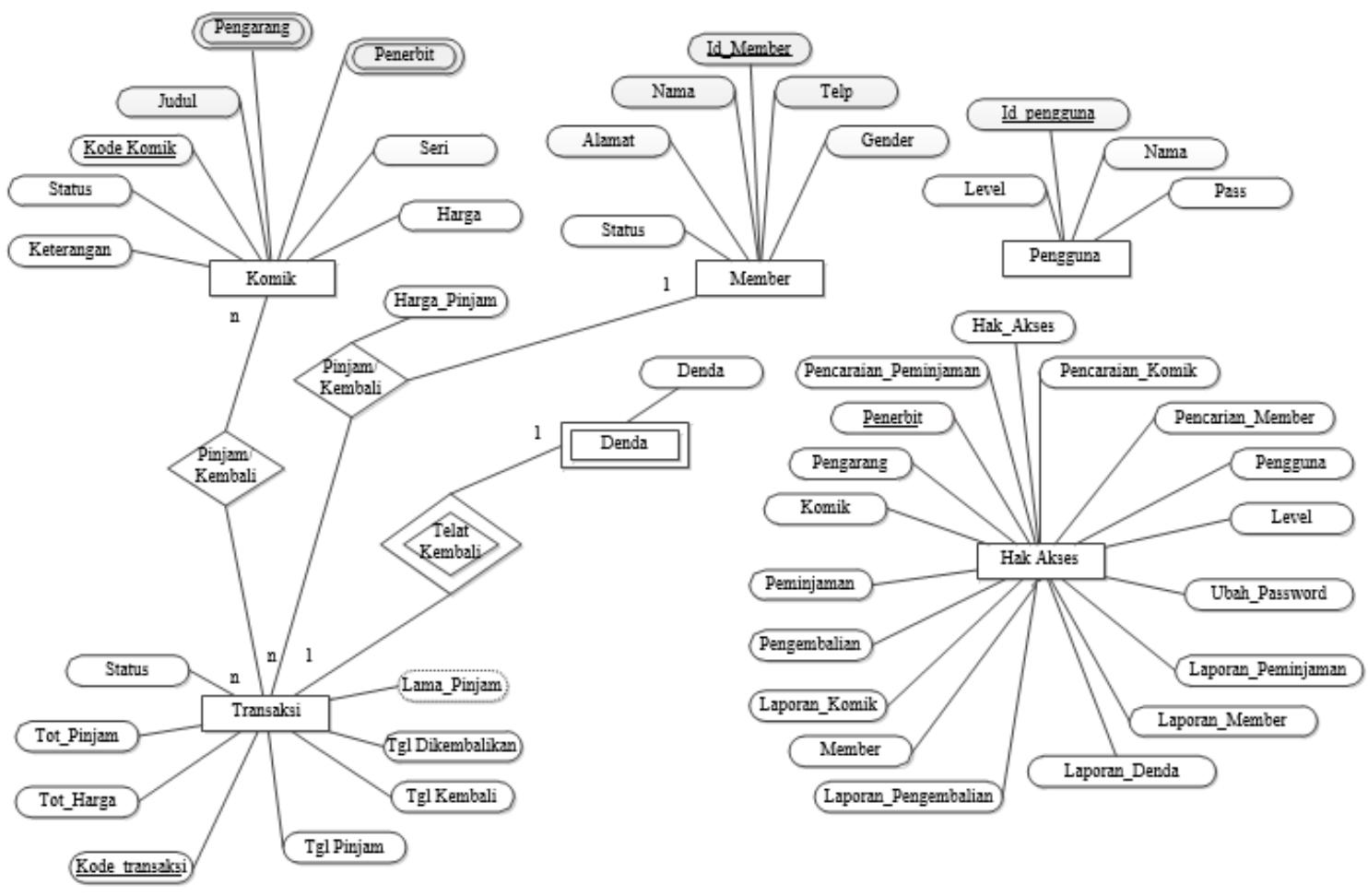

\section{Gambar 3 ERD Rental Komik}

3. Black Box Testing

Tabel 1 Black Box Testing

\begin{tabular}{|c|c|c|c|}
\hline No & Form & Pengujian & Keterangan \\
\hline 1 & Login & $\begin{array}{l}\text { Login menggunakan id pengguna dan } \\
\text { password }\end{array}$ & Sukses \\
\hline \multirow{3}{*}{2} & \multirow{3}{*}{ Pengguna } & Menyimpan data pengguna & Sukses \\
\hline & & Mengedit data pengguna & Sukses \\
\hline & & Menghapus data pengguna & Sukses \\
\hline 3 & Hak Akses & $\begin{array}{l}\text { Menentukan hak akses berdasarkan level } \\
\text { pengguna }\end{array}$ & Sukses \\
\hline \multirow{3}{*}{4} & \multirow{3}{*}{ Member } & Menyimpan data member & Sukses \\
\hline & & Mengedit data member & Sukses \\
\hline & & Menghapus data member & Sukses \\
\hline \multirow{3}{*}{5} & \multirow{3}{*}{ Pengarang } & Menyimpan data pengarang & Sukses \\
\hline & & Mengedit data pengarang & Sukses \\
\hline & & Menghapus data pengarang & Sukses \\
\hline \multirow{3}{*}{6} & \multirow{3}{*}{ Penerbit } & Menyimpan data penerbit & Sukses \\
\hline & & Mengedit data penerbit & Sukses \\
\hline & & Menghapus data penerbit & Sukses \\
\hline \multirow{3}{*}{7} & \multirow{3}{*}{ Komik } & Menyimpan data komik & Sukses \\
\hline & & Mengedit data komik & Sukses \\
\hline & & Menghapus data komik & Sukses \\
\hline
\end{tabular}




\begin{tabular}{|c|c|c|c|}
\hline \multirow[b]{2}{*}{8} & \multirow[b]{2}{*}{ Peminjaman } & Menyimpan data peminjaman & Sukses \\
\hline & & \begin{tabular}{|lll} 
Melakukan pencarian terhadap data \\
peminjaman
\end{tabular} & Sukses \\
\hline 9 & Pengembalian & Menyimpan data pengembalian & Sukses \\
\hline 10 & Laporan peminjaman & $\begin{array}{l}\text { Membuat laporan peminjaman harian, } \\
\text { mingguan dan bulanan }\end{array}$ & Sukses \\
\hline 11 & Laporan pengembalian & $\begin{array}{l}\text { Membuat laporan pengembalian harian, } \\
\text { mingguan dan bulanan }\end{array}$ & Sukses \\
\hline 12 & Laporan member & Membuat laporan seluruh member & Sukses \\
\hline 13 & Laporan komik & $\begin{array}{l}\text { Membuat laporan komik berdasarkan } \\
\text { kondisi, seri dan status }\end{array}$ & Sukses \\
\hline 14 & Laporan Denda & $\begin{array}{l}\text { Membuat laporan denda harian, } \\
\text { mingguan dan bulanan }\end{array}$ & Sukses \\
\hline
\end{tabular}

4. White Box Testing

Tabel 2 White Box Testing

\begin{tabular}{|c|c|c|c|}
\hline No & Form & Pengujian & Keterangan \\
\hline 1 & Login & $\begin{array}{l}\text { Jika password yang dimasukkan salah akan muncul } \\
\text { pesan tidak bisa login }\end{array}$ & Sukses \\
\hline 2 & Pengguna & $\begin{array}{l}\text { Jika ada salah satu text box yang kosong maka data } \\
\text { tidak akan bisa disimpan atau diedit }\end{array}$ & Sukses \\
\hline 3 & Member & $\begin{array}{l}\text { Jika ada salah satu text box yang kosong } \\
\text { maka data tidak akan bisa disimpan atau diedit }\end{array}$ & Sukses \\
\hline 4 & Pengarang & $\begin{array}{l}\text { Jika ada salah satu text box yang kosong maka data } \\
\text { tidak akan bisa disimpan atau diedit }\end{array}$ & Sukses \\
\hline 5 & Penerbit & $\begin{array}{l}\text { Jika ada salah satu text box yang kosong } \\
\text { maka data tidak akan bisa disimpan atau diedit }\end{array}$ & Sukses \\
\hline \multirow[t]{2}{*}{6} & \multirow[t]{2}{*}{ Komik } & $\begin{array}{l}\text { Jika ada salah satu text box yang kosong maka data } \\
\text { tidak akan bisa disimpan atau diedit }\end{array}$ & Sukses \\
\hline & & Text box harga hanya bisa diisi dengan angka & Sukses \\
\hline \multirow{4}{*}{7} & \multirow{4}{*}{ Peminjaman } & $\begin{array}{l}\text { Tgl kembali terhitung otomatis sesuai dengan lama } \\
\text { pinjam }\end{array}$ & Sukses \\
\hline & & $\begin{array}{l}\text { Perhitungan total pinjam dan total harga } \\
\text { dilakukan secara otomatis }\end{array}$ & Sukses \\
\hline & & Text box dibayar hanya bisa diisi dengan angka & Sukses \\
\hline & & $\begin{array}{l}\text { Perhitungan uang sisa dari pembayaran member } \\
\text { dilakukan secara otomatis }\end{array}$ & Sukses \\
\hline \multirow{3}{*}{8} & \multirow{3}{*}{ Pengembalian } & $\begin{array}{l}\text { Perhitungan denda dilakukan otomatis sesuai } \\
\text { dengan lama keterlambatan }\end{array}$ & Sukses \\
\hline & & Text box dibayar hanya bisa diisi dengan angka & Sukses \\
\hline & & $\begin{array}{l}\text { Perhitungan uang sisa dari pembayaran member } \\
\text { dilakukan secara otomatis }\end{array}$ & Sukses \\
\hline
\end{tabular}




\section{Manual Program}

Untuk menjalankan program sistem informasi rental komik pada taman bacaan conan ini dapat dilakukan dengan mengklik dua kali shortcut yang terdapat pada desktop, atau dapat juga dengan menjalankan file executable program (berekstensi .exe)

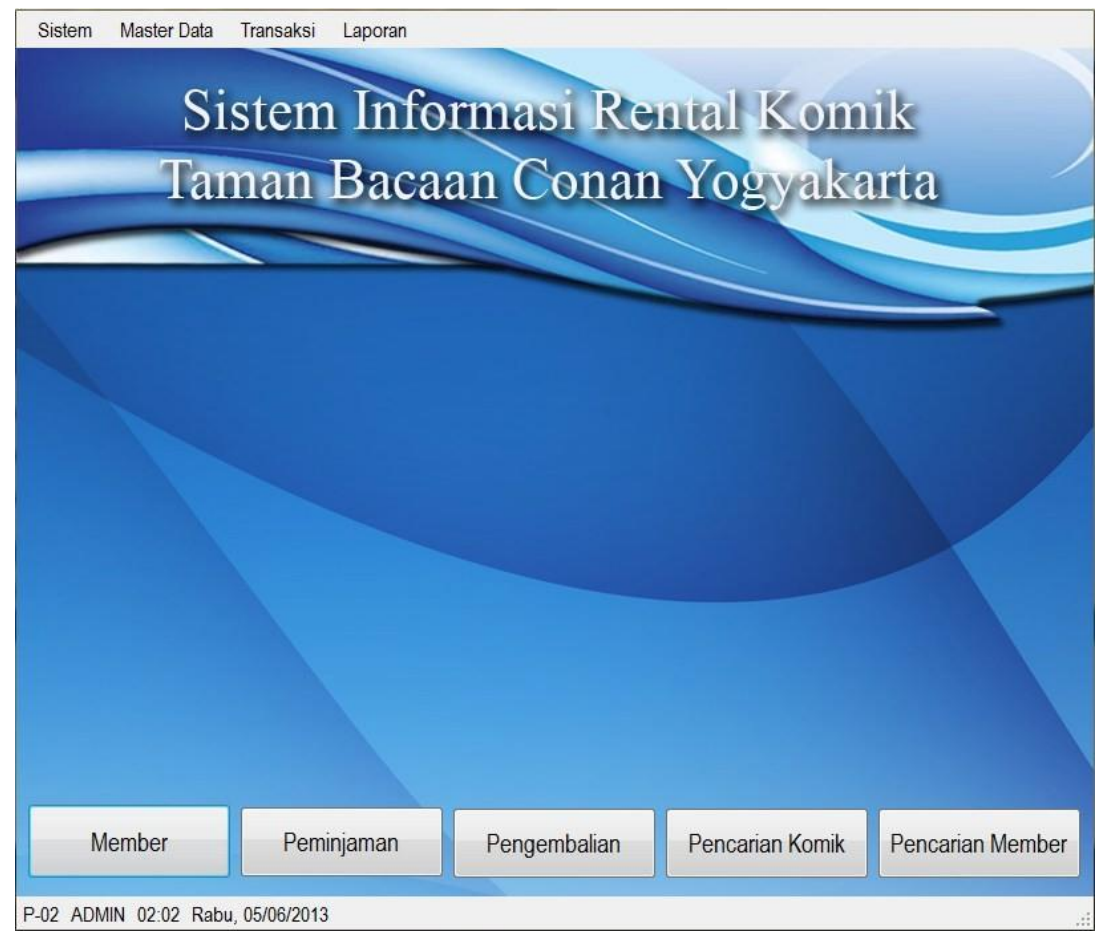

Gambar 4 Form Menu Utama

\section{KESIMPULAN}

\subsection{Kesimpulan}

Dari berbagai penjelasan yang telah diuraikan dalam laporan ini, maka dapat disimpulkan berbagai hal sebagai berikut :

1. Dengan adanya sistem informasi rental komik ini, di harapkan pihak taman bacaan conan dapat mencegah resiko kehilangan komik yang sering terjadi pada setiap bulannya.

2. Dengan adanya aplikasi yang baru ini dapat mempercepat dan memudahkan pekerjaan karyawan seperti pada proses pencatatan peminjaman, pengembalian, dan apabila ada data yang diperlukan dapat di peroleh dengan cepat.

3. Dengan adanya aplikasi yang baru ini, pihak taman bacaan conan dapat lebih mudah dalam membuat laporan karena sudah menggunakan sistem yang terkomputerisasi

\subsection{Saran}

Demi kelancaran operasional secara umum pada taman bacaan conan, maka perlu untuk diterapkan suatu aplikasi komputer secara terarah, terpadu dan menyeluruh. Penulis berusaha untuk mengajukan beberapa pemikiran berupa saran sebagai pertimbangan, antara lain:

1. Agar proses peminjaman dan pengembalian yang dilakukan hasilnya maksimum perlu ditinggkatkan ketelitian karyawan untuk menghindari terjadinya kesalahan dalam sistem. Untuk itu sangat diperlukan sekali bagi karyawan agar menguasai bidang komputer untuk mengelola transaksi penjualan melalui sistem komputer yang telah dibuat.

2. Aplikasi yang penulis buat ini hanya dapat digunakan untuk pengolahan data member, pengguna, pengarang, penerbit, komik, peminjaman dan pengembalian yang nantinya akan menghasilkan laporan. Aplikasi ini diharapkan nantinya dapat dikembangkan lagi sehingga 
memudahkan bagi karyawan dalam pengolahan data peminjaman dan pengembalian pada taman bacaan conan sehingga dapat menghasilkan informasi yang lengkap dan sempurna. Seperti pada proses peminjaman dan pengembalian agar proses berlangsung lebih cepat lagi dapat di gunakan barcode scanner.

\section{REFERENSI}

[1] Syahrul dkk, "Teknologi informasi dan pendidikan," Al-Manar (Edisi 1), vol. 11, no. 2, pp. 17, 2004.

[2] Satriaji Nur Prasetya, "Rancang Bangun Sistem Informasi Koperasi Simpan Pinjam Sejahtera Berbasis Java," J. Fasilkom, vol. 10, no. 3, pp. 271-276, 2020, doi: 10.37859/jf.v10i3.2266.

[3] H. Antonio and N. Safriadi, "Rancang Bangun Sistem Informasi Administrasi Informatika ( SIADIF )," vol. 4, no. 2, pp. 12-15, 2012. 